\title{
Experimental Investigation and Numerical Modeling of Surge Currents in Lightning Protection System of a Small Residential Structure
}

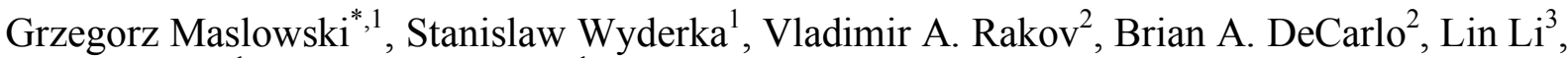 \\ Jerzy Bajorek ${ }^{1}$ and Robert Ziemba ${ }^{1}$ \\ ${ }^{I}$ Rzeszow University of Technology, Poland \\ ${ }^{2}$ University of Florida, USA \\ ${ }^{3}$ North China Electric Power University, China
}

\begin{abstract}
The distribution of lightning current in the lightning protection system (LPS) and the electrical circuit of two test structures simulating residential buildings was experimentally studied at two research facilities in Florida and in Poland. In Florida, the experiments were conducted using rocket-triggered lightning, and in Poland a mobile current surge generator was employed. The soil in Florida was sandy, while in Poland it was mostly clay. Simulations of lightning current in the LPS and the electrical circuit of each of the test structures were also performed. In this paper, we present results of experiments and numerical modeling of lightning current distribution in different configurations of LPS installed on the test structures at the two sites.
\end{abstract}

Keywords: Grounding, lightning, lightning electromagnetic field, lightning protection system (LPS)

\section{INTRODUCTION}

In order to examine the distribution of lightning current in the lightning protection system (LPS) and the electrical circuit of a small structure simulating residential building, the experiments were conducted at the International Center for Lightning Research and Testing (ICLRT) at Camp Blanding, Florida, in 1997. The simple grounding system of the structure which consisted of two grounding rods was subjected to lightning discharges triggered from thunderclouds using the rocket-and-wire technique. The peak value of the current entering the electrical circuit of the structure was found to be over $80 \%$ of the injected lightning current peak, in contrast with the $25 \%$ or $50 \%$ assumed in two IEC-suggested scenarios. Also, the percentages of current flowing to the transformer secondary neutral via a 50-m underground cable and current flowing through the SPDs to the electrical circuit of the structure were observed to be approximately a factor of two to four greater than those assumed by IEC. A detailed description of this experiment is found in [1].

For further examination of lightning current distribution in the LPS and the electrical circuit of a residential building the experiments were continued at the ICLRT in 2004 and 2005 [2]. A new test structure (Test House), typical of Florida housing, was constructed at the ICLRT for these experiments (see Fig. 1a).

Two years later, in 2007 and 2008, similar experiments were conducted at the Rzeszow University of Technology (RUT), Poland, using a mobile current surge generator and

*Address correspondence to this author at the Rzeszow University of Technology, Poland; Tel: + 4817 8651253; Fax:+ 4817 8542088;

E-mail: maslowski@prz.edu.pl three different configurations of LPS installed on a simple model of residential building [3] (see Fig. 1b).

A primary objective of experiments at the ICLRT and at the RUT was to examine the current waveforms in different parts of the circuit and the division of the injected surge current between the grounding system of the LPS and remote ground.

Interpretation of the experimental results was not straightforward. Therefore, in order to get a better insight into to experimental data of lightning current distribution in the LPS and the electrical circuit of each test structure, the numerical analysis was conducted. For numerical simulation of the University of Florida (UF) experiments, the models based on the lumped circuit theory and full-wave approach in the frequency domain were used [4]. In the case of investigations conducted at the RUT, a frequency domain full-wave approach implemented in the SES software package was employed $[5,6]$.

\section{EXPERIMENTAL SETUPS}

Relative positions of the Test House and tower launcher at the ICLRT are shown in Fig. (2). The distance between the central point of the building and the launcher $11 \mathrm{~m}$ height is roughly $27 \mathrm{~m}$. The lightning current injection points on the roof of the Test House were point Q (south air terminal) in 2004 and point $\mathrm{P}$ (instrumentation box connected to the LPS in the middle of the roof) in 2005.

Florida, 2004. Examination of lightning current distribution was curried out in 2004 on the LPS shown schematically in Fig. (3a). Three air terminals interconnected by a horizontal wire were installed on the roof ridge of the Test House. Two down conductors connected this horizontal wire to two pairs of ground rods at opposite corners (NE and $\mathrm{SW}$ ) of the Test House. Within each pair, the rods were 


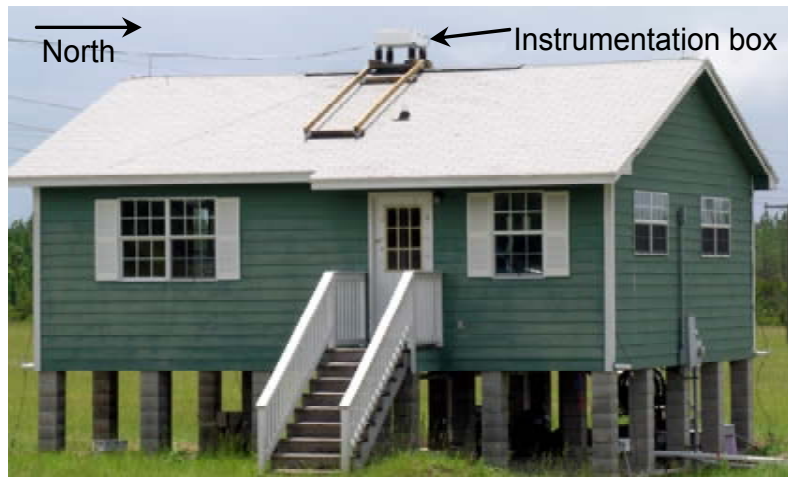

(a)

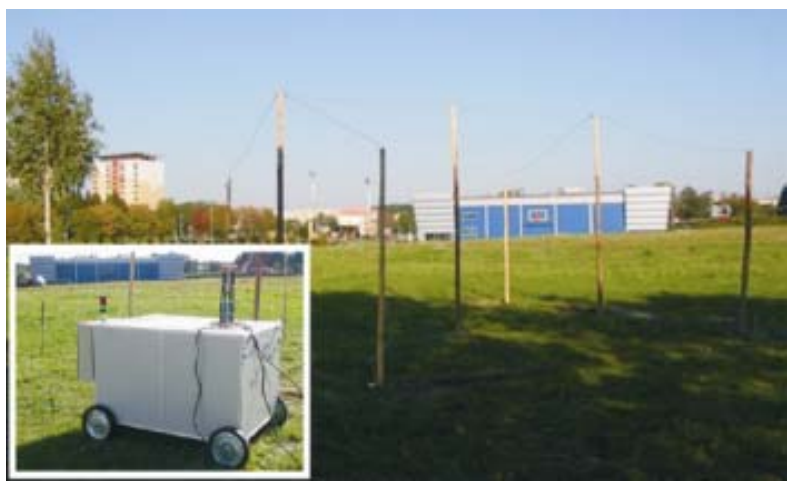

(b)

Fig. (1). The setups of test structures: (a) the Test House with LPS at Camp Blanding, lightning triggering site in Florida; (b) the experimental setup with current surge generator and LPS mounted on wooden poles at Rzeszow University of Technology, Poland.

about $6.1 \mathrm{~m}$ apart and were connected by a buried horizontal conductor. In the middle of the north side of the Test House there was another ground rod, the power supply system ground rod, connected by a buried horizontal conductor approximately $3.4 \mathrm{~m}$ long to the LPS ground rod at the NE corner (see Fig. 3a). The total number of ground rods was five. Each of the five ground rods at the Test House had a length of $2.7 \mathrm{~m}$. An electrical diagram of this setup is shown in Fig. (3b). The electrical circuit and the load of the Test House were simulated by two resistors (4 and $6 \Omega$ ). MOV surge protective devices (SPDs) were installed between each phase conductor and the grounded neutral. A watt-hour meter was installed between the electrical circuit and the underground $600-\mathrm{V}$ triplexed cable, which was not energized.

The other end of the $600-\mathrm{V}$ cable was terminated at Instrumentation Station 1 (IS1), $50 \mathrm{~m}$ away, with $50-\Omega$ resistors. The cable neutral was grounded at IS1 using a single vertical ground rod with a length of $12 \mathrm{~m}$. The measured dc grounding resistances for each grounding location are given in Fig. (3b). The dc grounding resistance of the entire system buried was $113 \Omega$. Grounding resistances were measured using the fall-of-potential method.

The lightning current was directed, via a 32-m long metallic conductor, from the tower launcher to south air terminal of the Test House (point Q in Fig. 2). The incident lightning current was measured at the launch tower. Lightning currents in the LPS and electrical circuit conductors were measured at six points, labeled A, B, C, D, $\mathrm{G}$, and $\mathrm{K}$ (see Fig. 3a, b). Points $\mathrm{A}$ and $\mathrm{B}$ were on down conductors at the Test House SW and NE corners, respectively. Point $\mathrm{C}$ was the power supply system ground, and point $\mathrm{G}$ was the ground at IS1. Point D was on the grounding conductor connecting the power entry box (service entrance panel) to the power supply system ground rod. $1-\mathrm{m} \Omega$ shunts were used to measure the currents at points A, B, C, D and G, while the Pearson 110-A current transformer was used to measure the current at point $\mathrm{K}$.

Florida, 2005. The LPS for the 2005 experiment differed from the LPS installed in 2004. The 2005 setup consisted of two interconnected air terminals, four down conductors, and five ground rods (four for the LPS, one at each corner, and one for the power supply system) interconnected by a buried loop conductor called also a ring electrode or counterpoise (see Fig. 3c). An electrical diagram of this setup is shown in Fig. (3d). Each LPS vertical ground rod had a length of 2.7 $\mathrm{m}$, and the power supply system ground rod had a length of 3 $\mathrm{m}$. The connections of the $600-\mathrm{V}$ cable at IS1 were as in 2004. Measured dc grounding resistances for each grounding location are given in Fig. (3d). The dc grounding resistance of the entire Test House grounding system buried was $121 \Omega$.

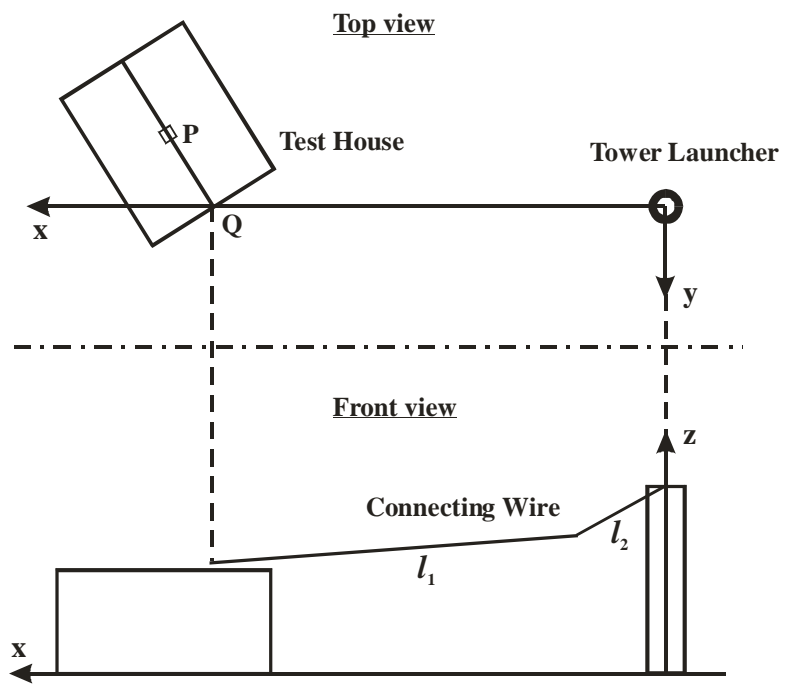

Fig. (2). Relative positions of the Test House, tower launcher, and connecting wire. Q and P are current injection points in 2004 and 2005, respectively (adapted from [4])

The lightning current was directed from the tower launcher to the middle point of the Test House roof ridge, where it was measured in the instrumentation box (see Fig. 1a), and then injected into the horizontal conductor connecting two air terminals at the ends of the ridge. Currents were measured, using $1-\mathrm{m} \Omega$ shunts, at six points, labeled A, A1, B, B1, D, and G (see Fig. 3c, d).

Poland, 2007 - 2008. Investigation results on lightning current distribution in LPS of residential building obtained at the ICLRT, Florida, provided inspiration to conduct similar studies at the RUT, Poland. It was decided to construct a 
residential building model (Test House) and to install an LPS, electrical circuit and feeding underground cable, all these elements being similar to the ones used at the ICLRT in 2004 and 2005. Substantial difference was the surge current source. Lightning current pulses were simulated by surges produced by a mobile current surge generator (see Fig. 1b). The main parameters of the generator are: maximum storage energy $10 \mathrm{~kJ}$, operating voltage $10-80 \mathrm{kV}$, maximum surge current $50 \mathrm{kA}$.

A simplified scheme of the entire test system at the RUT in Poland is shown in Fig. (4a). The test structure composed of wooden poles was built on flat clayey terrain close to the grounding system of street lights. This grounding system was connected to the casing of the generator by three insulated parallel copper conductors (each having the crosssection area of $50 \mathrm{~mm}^{2}$ ) to form a return path for the current injected from the generator to the LPS. The lengths of these conductors are given in Fig. (4a).

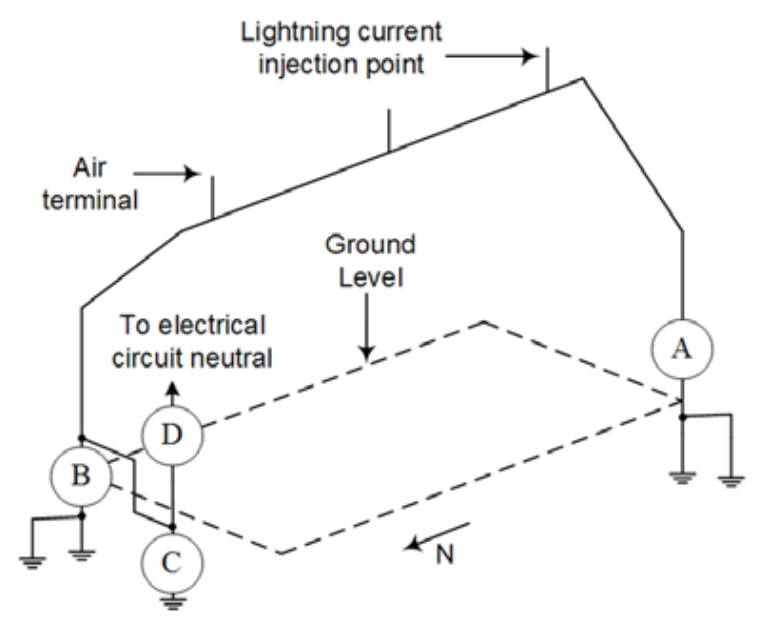

(a)

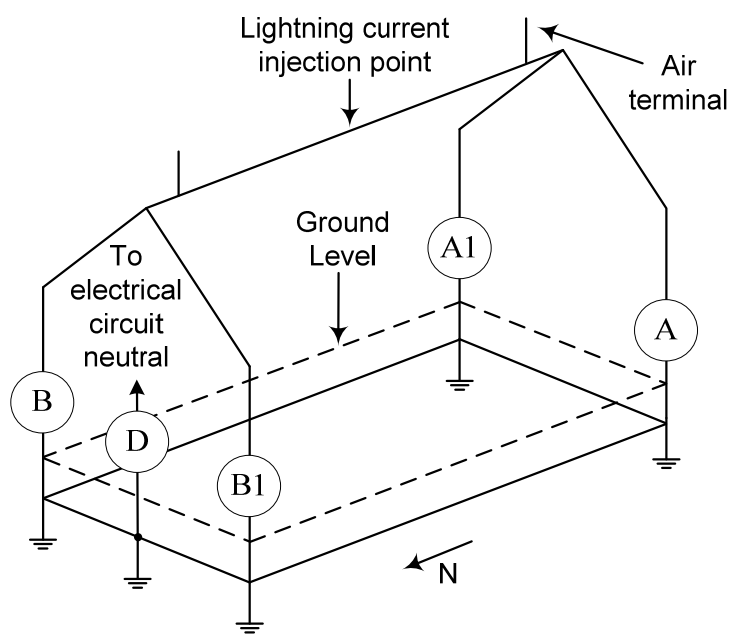

(c)
Three different LPS configurations (LPS 1a, LPS $1 b$ and LPS 2) were used to examine surge current distribution. For each configuration the horizontal air terminal was installed on the simulated roof ridge. In LPS 1a, shown in Fig. (4b), there were two down conductors connecting the air terminal to grounded vertical rods, each $1.5 \mathrm{~m}$ long, at two adjacent corners of the test structure. The configuration labeled LPS 1b, shown in Fig. (4c), had two down conductors connected to two vertical ground rods, each $1.5 \mathrm{~m}$ long, placed at opposite corners of the test structure. Each of these rods was connected using a buried conductor to the $4.5 \mathrm{~m}$ long vertical rod driven in soil $5 \mathrm{~m}$ away. LPS 2, shown in Fig. (4e), had four down conductors connecting the air terminal to vertical ground rods, each $1.5 \mathrm{~m}$ in length, placed at all the test structure corners and interconnected by a buried loop conductor (ring electrode). Each of these configurations included an additional power supply system vertical ground rod, $1.5 \mathrm{~m}$ in length, in the middle of one side of the structure. In LPS 1a and LPS $1 \mathrm{~b}$, the power supply system

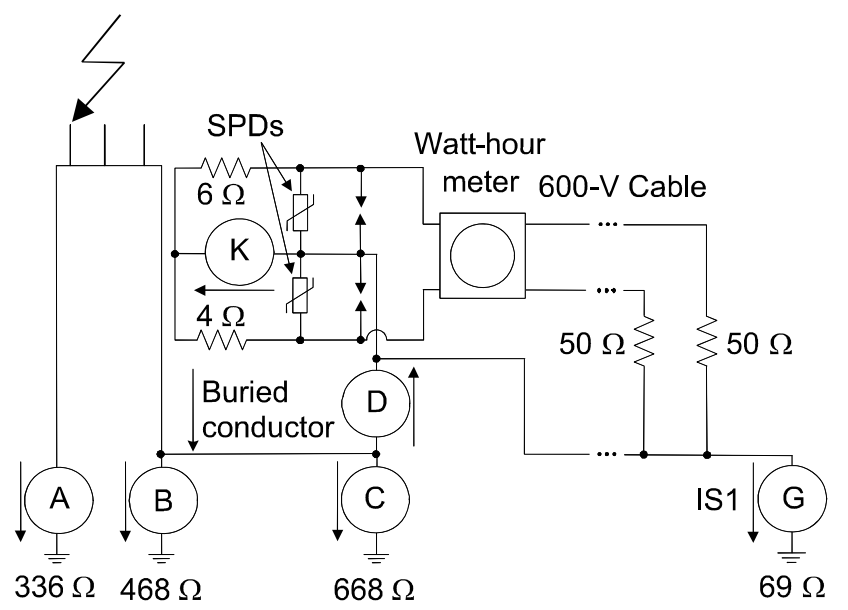

(b)

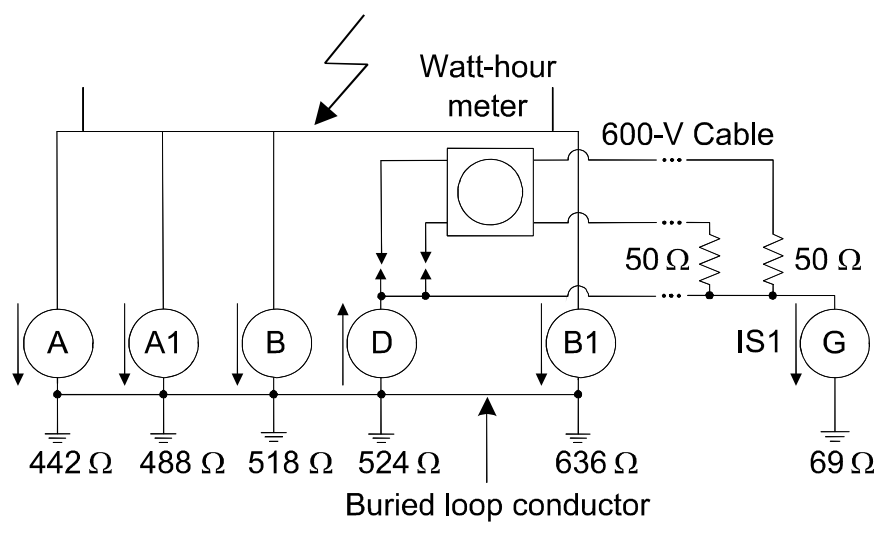

(d)

Fig. (3). (a) Diagram of the lightning protection system of the Test House in Florida in 2004. (b) Electrical diagram of test system configuration for 2004. Currents A, B, C, D, and K were measured at the Test House, and current G was measured at Instrumentation Station (IS1), $50 \mathrm{~m}$ away. (c) Diagram of the lightning protection system of the Test House in Florida in 2005. (d) Electrical diagram of the test system configuration for 2005. Currents A, A1, B, B1, and D were measured at the Test House, and current G was measured at IS1. 


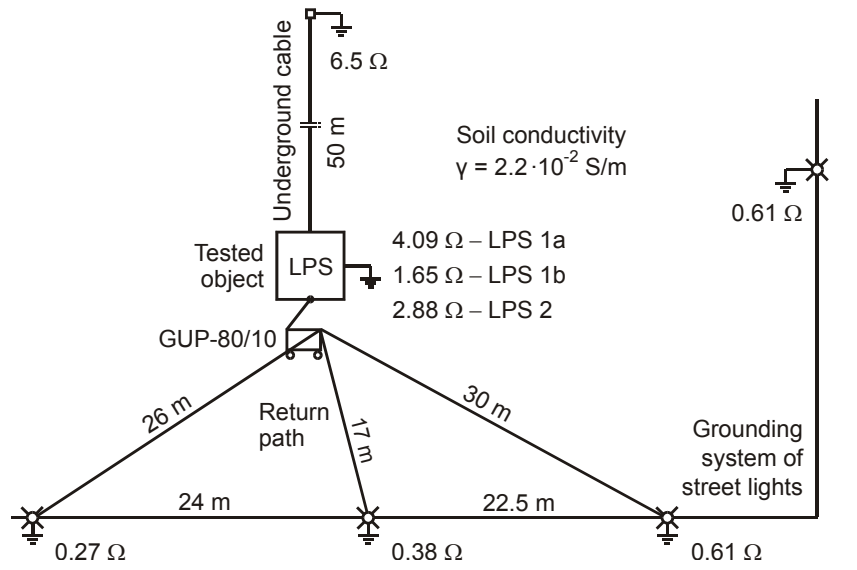

(a)

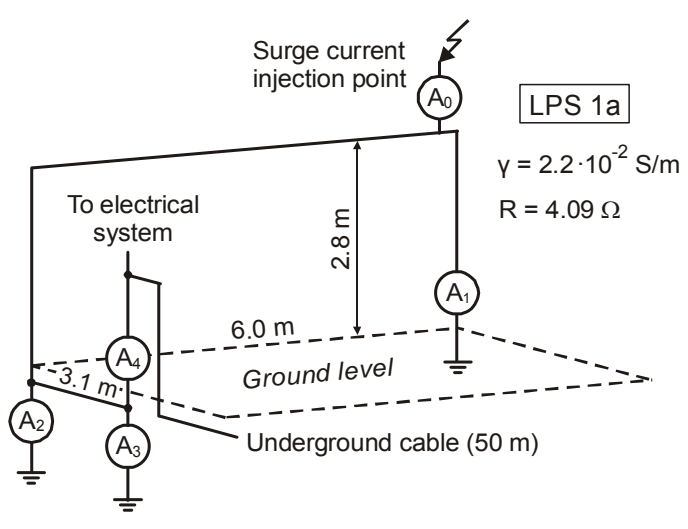

(b)

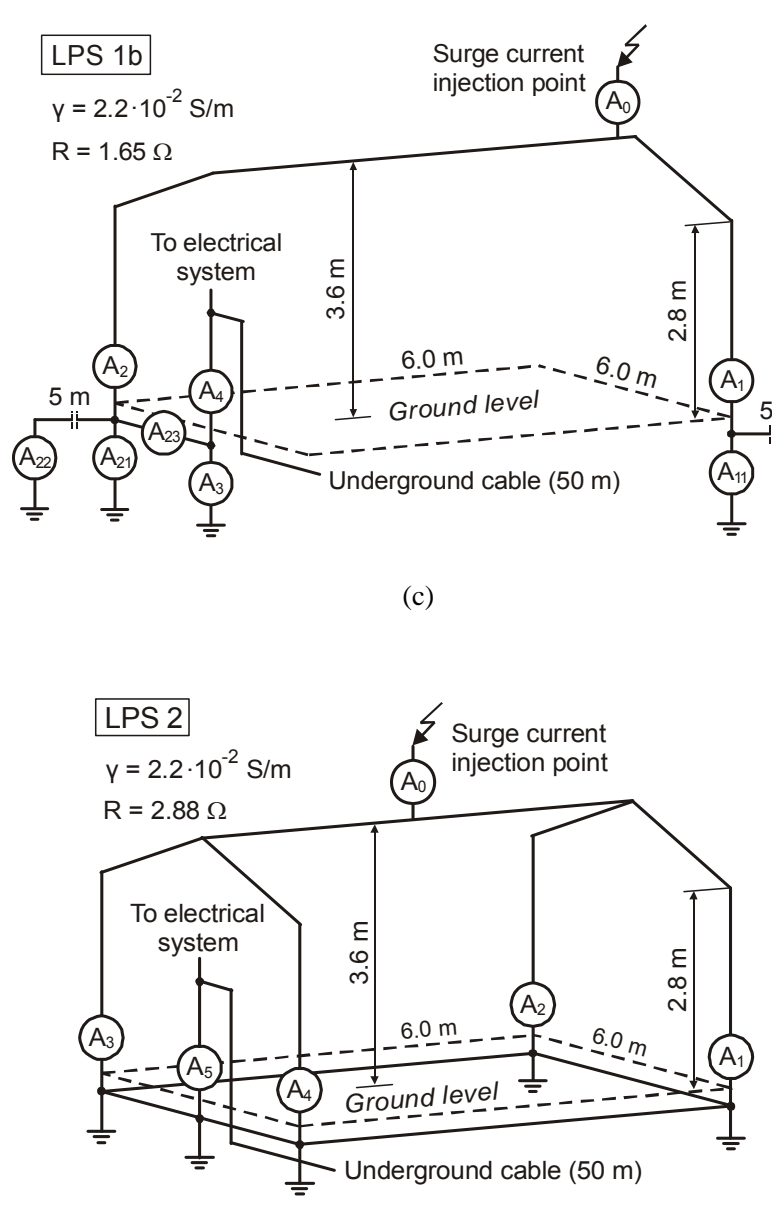

(e)

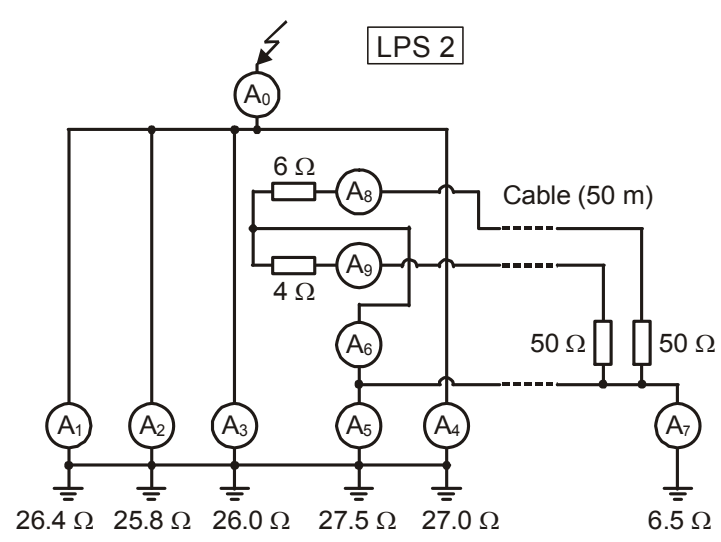

(f)

Fig. (4). (a) Diagram (plan view) of the entire test system in Poland which consists of the LPS, the house electrical circuit connected to remote ground via a 750-V underground cable, and return path to the surge generator. (b) Configuration of LPS $1 \mathrm{a}$, which was initially installed and tested in 2007. (c)-(f) Configurations of LPS 1b and LPS 2 together with their electrical diagrams which include the power feeder whose neutral is grounded $50 \mathrm{~m}$ away. Current measured at point A4 flows to remote ground for LPS 1a and LPS 1b, while for LPS 2 this current was measured at point A5. LPS 1b and LPS 2 were tested in summer 2008.

ground rod was connected to the neighboring LPS ground rod by a buried horizontal conductor. In the case of LPS 2 , the power supply system ground rod was connected to the loop conductor.

Electrical diagrams of configurations LPS $1 \mathrm{~b}$ and LPS 2 are presented in Fig. (4d, f), respectively. The electrical circuit and the load of the test structure were simulated, the same way as at the ICLRT, by two resistors (4 and $6 \Omega$ ) installed on the central pole of the test structure and connected to the underground YDY $-3 \times 2.5-\mathrm{mm}^{2} 750-\mathrm{V}$ cable. The other end of the cable was terminated $50 \mathrm{~m}$ away with $50 \Omega$ resistors. The cable neutral was grounded at this 
end using four vertical ground rods, each $1.5 \mathrm{~m}$ long, located at the corners of a square having the side length of $1 \mathrm{~m}$. Such configuration enabled us to obtain a relatively small resistance of the remote ground. The dc grounding resistances, depicted in Fig. $(\mathbf{4 b}, \mathbf{d}, \mathbf{f})$, for each grounding location, were measured using the Wenner method with three probes [7].

Soil conductivity at the site where the test system was built has been measured using the four-probes Wenner method and its value for all experiments conducted in Poland was approximately $2.2 \cdot 10^{-2} \mathrm{~S} / \mathrm{m}$. The dc grounding resistance of the entire buried system, excluding the remote ground and the grounding system of street lights, was equal $4.09 \Omega, 1.65 \Omega$ and $2.88 \Omega$ for LPS $1 \mathrm{a}$, LPS $1 \mathrm{~b}$ and LPS 2 , respectively. The dc resistance of the cable neutral grounded at the remote end was $6.5 \Omega$ in each case. Currents were measured at points labeled $\mathrm{A}_{0}$ (injection point), $\mathrm{A}_{1}, \mathrm{~A}_{2}$ and so on. At all the points, $10-\mathrm{m} \Omega$ shunts, with nominal surge current $5 \mathrm{kA}$, response risetime $1.8 \mathrm{~ns}$, and frequency band $200 \mathrm{MHz}$, were used to measure the currents flowing in different parts of the LPS.

\section{EXPERIMENTAL AND COMPUTATIONAL RESULTS AND DISCUSSION}

In the 2004 experiment at the ICLRT, two lightning flashes were triggered to the Test House. For Stroke 3 of a nine-stroke flash 0401, injected lightning current and currents at points $\mathrm{A}, \mathrm{B}$, and $\mathrm{C}$, and currents at points D and $\mathrm{K}$ are shown in Fig. (5). The current waveforms in rods $\mathrm{A}, \mathrm{B}$ and $\mathrm{C}$ are dominated by higher-frequency current components flowing to ground locally, while the one at point D primarily contains lower-frequency components traveling to remote ground $50 \mathrm{~m}$ away.

In the 2005 experiment at the ICLRT, eight lightning flashes were triggered to the Test House. Selected data for one stroke (0521-1) are shown in Fig. (6). The sum of four down-lead currents minus the current at point $\mathrm{D}$ represents the current going to the grounding system of the Test House, the latter being compared to the injected current in Fig. (6). Note that the current to the local grounding system, (Sum -
D), is normalized to the injected current in order to compare only the waveshapes. It is clear from Fig. (6) that the lowerfrequency components of the injected current tend not to go to the grounding system of the Test House and find their way to the remote ground. In 2004, the mean value of the peak current entering the electrical circuit neutral was about $22 \%$ of the injected lightning current peak, while in 2005 it was about $59 \%$. Discussion of these results is found in [2].

In the computer simulations of the UF experiments, the current distribution was modeled using the lumped circuit theory in the frequency domain. The injected lightning current was represented in the model by an ideal current source. The effect of electromagnetic field radiated by the lightning channel was also accounted for in the model (for one tested configuration). In field calculations, the lightning channel and the wire connecting the rocket launcher and the Test House were modeled as vertical and horizontal electric dipoles above lossy ground. The discrete complex images method was used to calculate the electromagnetic field radiated by the electric dipoles. The time-domain current waveforms were obtained by means of the inverse Fourier transform. Finally, the calculated currents in the LPS were compared with those measured.

The modeling of the LPS tested in 2004 was done for two cases. The first one concerned a lumped circuit model without electromagnetic coupling between lightning channel and LPS, while the second case concerned a lumped circuit model with such coupling. The calculations were referred to the experimental data for Stroke 0401-3 having a peak current of $11 \mathrm{kA}$. Calculated and measured currents are shown in Figs. $(\mathbf{7}, \mathbf{8})$ for the model without and with the coupling, respectively.

The modeling of the LPS tested in 2005 was done for the case concerned a lumped circuit model without electromagnetic coupling between lightning channel and LPS. The calculations were referred to the experimental data for Stroke 0521-1 having a peak current of $6.8 \mathrm{kA}$. Calculated and measured currents are shown in Fig. (9).

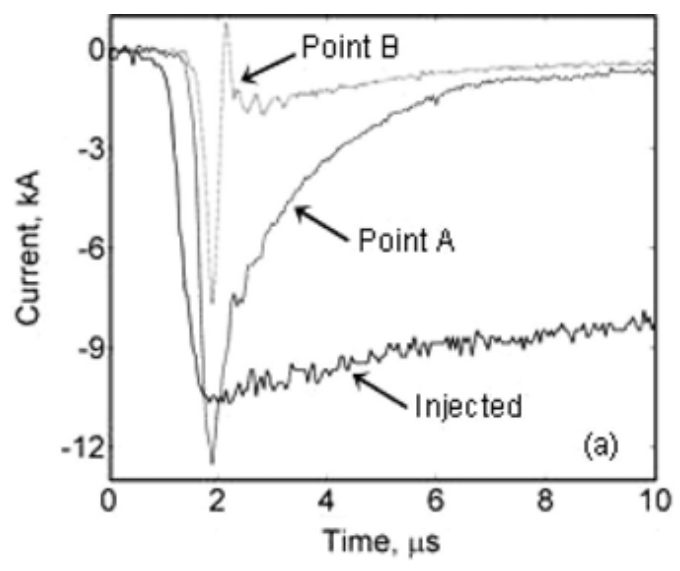

(a)

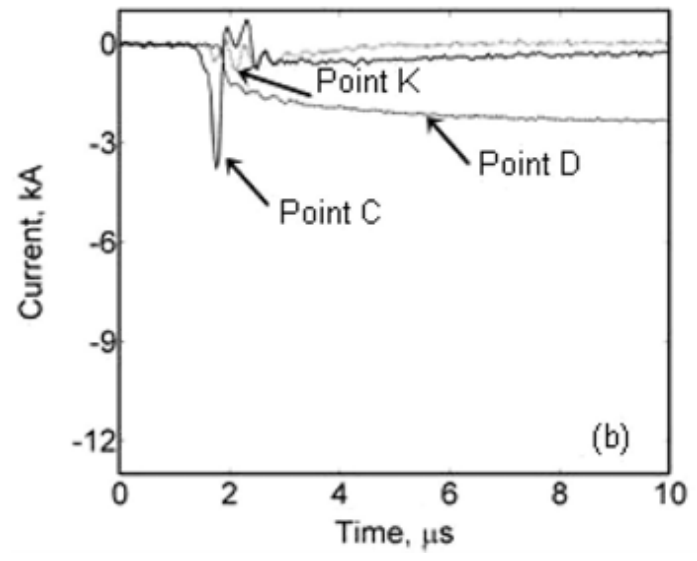

(b)

Fig. (5). Return-stroke currents for Stroke 0401-3: (a) injected current and currents at points A and B; (b) currents at points C, D, and K, see Fig. (3a, b) (adapted from [2]). 
The modeling results show that the distribution of currents in the LPS tested in 2004 (Figs. 7, 8) is significantly influenced by the electromagnetic field of lightning channel and connecting wire. This influence was considerably weaker in the LPS tested in 2005 (Fig. 9). This is, at least in part, is related to the differences in the two tested configurations. The conductors of LPS tested in 2004 (two down conductors) were arranged to form only one main loop, but the conductors of LPS tested in 2005 (four down conductors interconnected by a buried loop conductor) formed a cage. It is likely that the electromagnetic coupling between the lightning channel and the different loops of the LPS tested in 2005 tended to cancel each other. Moreover, the induced effects depend also on the relative positions of the Test House and the tower launcher, orientation of the lead conductor, and the current injection point.

One of the causes of the differences between the measurements and simulations were errors in the calculations. Main sources of these errors were the approximate formulae used to calculate the circuit parameters. The nonzero value at the beginning of the determined waveforms are caused by the numerical convolution used in the calculation of circuit responses. Peak values and tail portions at the waveforms are not materially affected by these errors. For the lightning pulses having a nonzero constant component, an inherent systematic error exists when the FFT-IFFT algorithm is used to obtain the transient responses, such as the induced voltages on the transmission lines. A theorem for this problem was introduced in [8]. According to the theorem, the error depends not only on the shape of the lightning pulse but also on the transfer function. More details on the simulation of the UF experiments are found in [4].

For the experiments at the RUT, Poland, the injected current and currents in different parts of the LPS $1 \mathrm{a}$, LPS $1 \mathrm{~b}$ and LPS 2 are shown in Fig. (10). As one can see in Fig. (10a), current waveforms in ground rods $A_{1}, A_{2}$ and $A_{3}$ of LPS 1a differ significantly from the injection current waveform and the current waveform entering the cable neutral. Shown in Fig. (10b) is the division of current $A_{2}$ into three current components measured at points $\mathrm{A}_{21}, \mathrm{~A}_{22}$ and $\mathrm{A}_{23}$. Again, the registered waveforms are not the same and they depend on grounding resistances of ground rods.

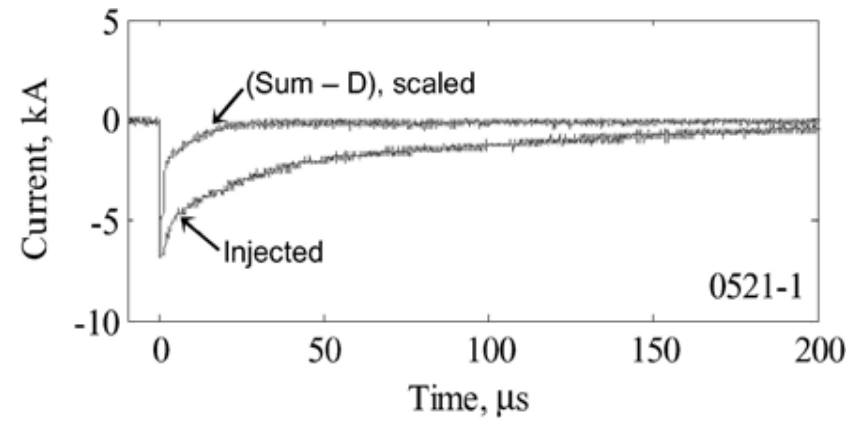

Fig. (6). Comparison of injected return stroke current and the difference between the sum of the four down-lead currents and current D, for Stroke 0521-1, (adapted from [2]).

Considerably higher resistance of ground rod $\mathrm{A}_{21}$ appears to have greater influence than longer current paths to the ground rods $A_{22}$ and $A_{3}$. As shown in Fig. (10c), almost equal division of the injection surge current between four ground rods of LPS 2 results from close values of their grounding resistances and from connection of them to the loop conductor (see Fig. 4e, f).

The injected current, current flowing to the LPS ground and current going to electric circuit and underground cable are shown in Fig. (11), for each of the configurations investigated in Poland. Current waveforms measured at points $A_{4}$ and $A_{5}$ (see Fig. 4), which were going to the remote ground, were practically the same as those measured $50 \mathrm{~m}$ away at point $\mathrm{A}_{7}$. For LPS 1a the value of the peak current entering the electrical circuit neutral was about $56 \%$ of the injected current peak, and for LPS $1 \mathrm{~b}$ it was about $16 \%$. For LPS 2 this ratio was $21 \%$.

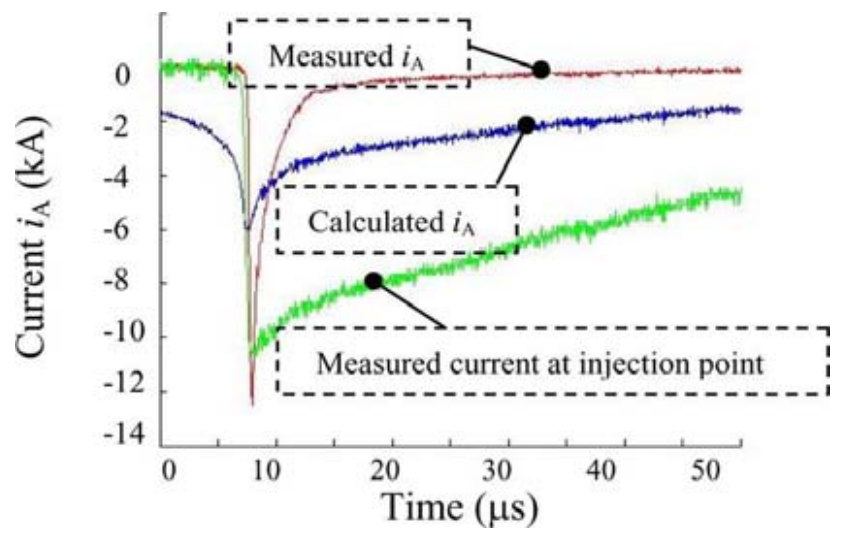

Fig. (7). UF experiments. Calculated and measured waveforms for $i_{A}$ and measured waveform for the current at injection point (Stroke 0401-3). Electromagnetic coupling is neglected, (adapted from [4]).

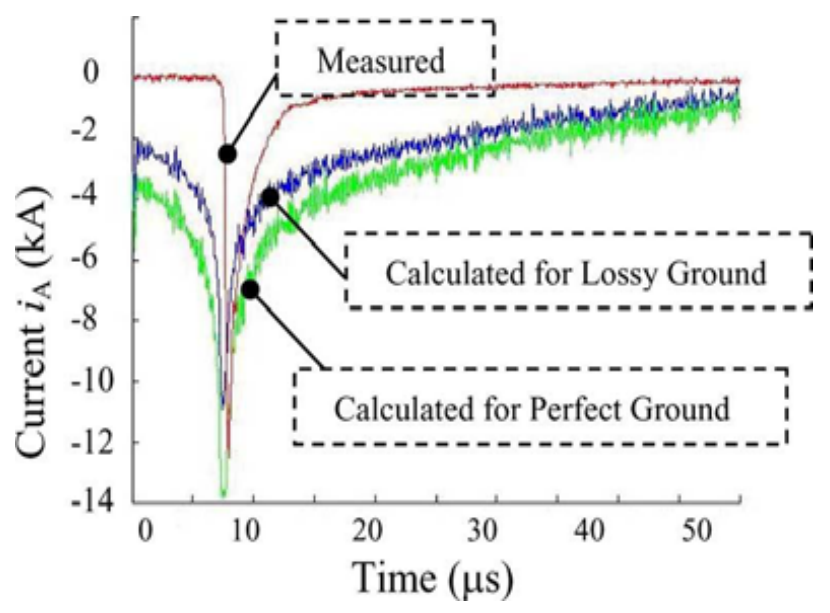

Fig. (8). UF experiments. Calculated and measured waveforms for $i_{A}$ (Stroke 0401-3). Electromagnetic coupling between the lightning channel and the LPS is included in the model (adapted from [4]).

The waveforms of current entering the neutral of cable which were measured at points $A_{4}$ and $A_{5}$ (Figs. 10, 11) are less steep (amplitudes of higher-frequency components are attenuated significantly) than waveforms of the injected current and of the currents going to the grounding system of LPS.

These results are consistent with those obtained in the experiments for sandy soil at Camp Blanding, Florida [2]. This effect was clearly visible for LPS 1a (Figs. 10a, 11a), 
and less pronounced but detectable for LPS $1 \mathrm{~b}$ and LPS 2 with the relatively low dc grounding resistance of the entire system (Fig. 11b, c).

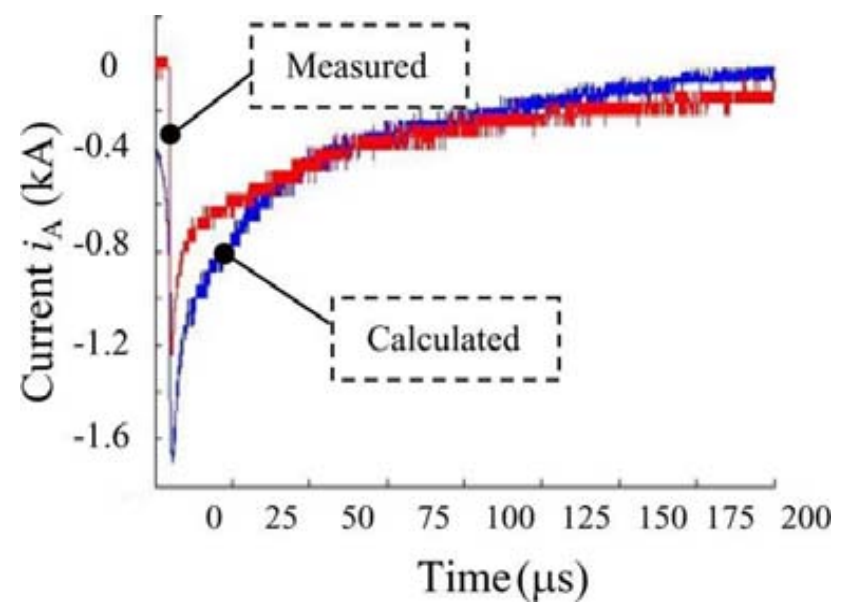

Fig. (9). UF experiments. Calculated and measured waveforms for $i_{A}$ (Stroke 0521-1). Electromagnetic coupling is neglected, (adapted from [4]).

For the experiments conducted at the RUT, calculations of surge currents were done using full-wave approach implemented in the SES software package [5, 6]. During numerical analysis the following assumptions for the physical model were adopted:

- $\quad$ air and ground are homogeneous media,

- $\quad$ the ground and wires have defined real parameters and are linear and isotropic media,

- a thin-wire approximation is applied in relation to cylindrical wires forming the studied system $[9,10]$,

- $\quad$ the forcing function representing the lightning current is realized in the form of an ideal current generator with one electrode connected to lightning protection system and the other is connected to ground at the infinity, whereas the effect of those electrodes is neglected.

The method employed for computation is based on the analysis of the studied system in the frequency domain. The input current sources were defined arbitrarily and they were practically the same as those injected during experimental tests with the mobile generator. Wires of the modeled LPS were subdivided into segments in which the surface boundary condition had to be satisfied for the axial electric field component

$\mathbf{t} \cdot\left(\mathbf{E}^{i}+\mathbf{E}^{s}\right)=I_{l} Z_{w}$

where $\mathbf{E}^{s}$ is scattered electric field generated by current in the analyzed segment due to existence of incident electric field $\mathbf{E}^{i}, I_{l}$ is the current flowing in the segment, $Z_{w}$ is the internal impedance of the wire, whereas $\mathbf{t}$ is a unitary vector tangential to segment surface.

From the Maxwell equations and Eq. (1) a relationship may be derived to relate the current flowing along wire axis due to incident electrical field tangential to wire surface [5].

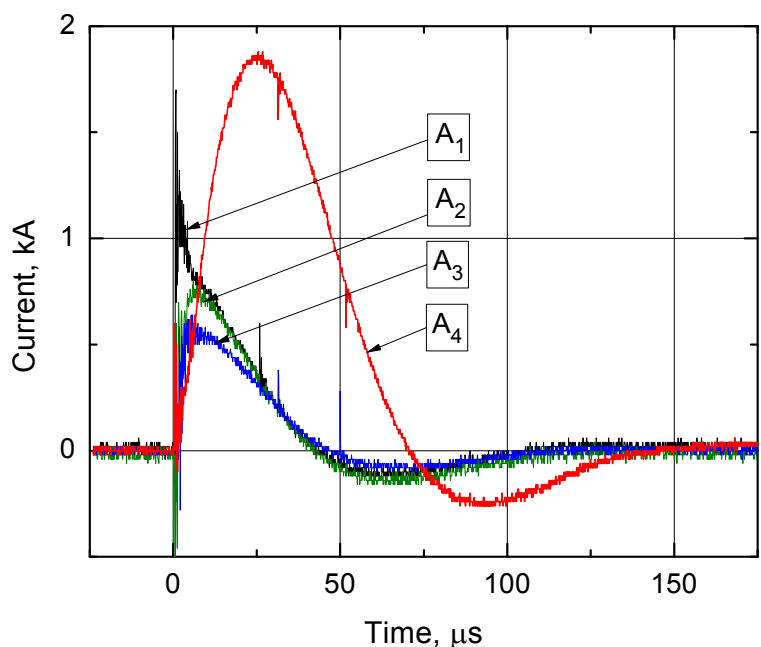

(a)

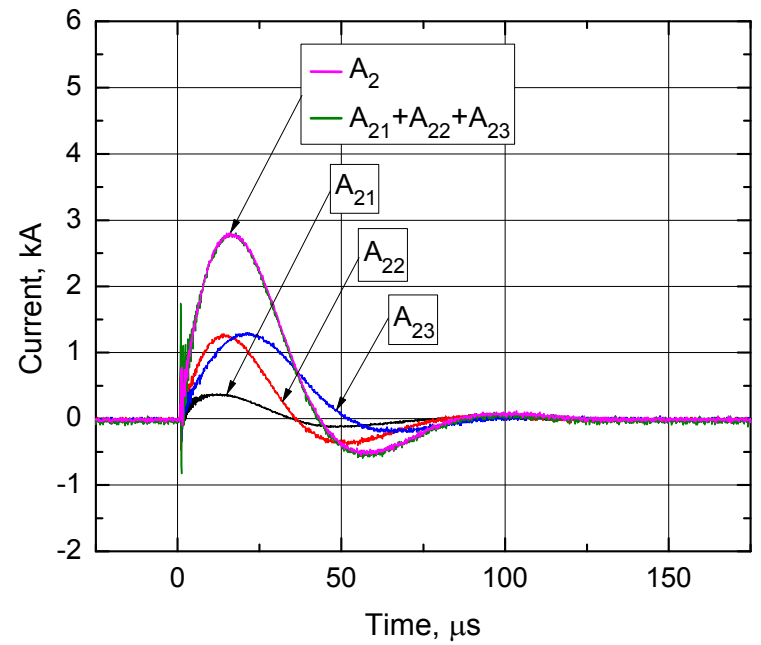

(b)

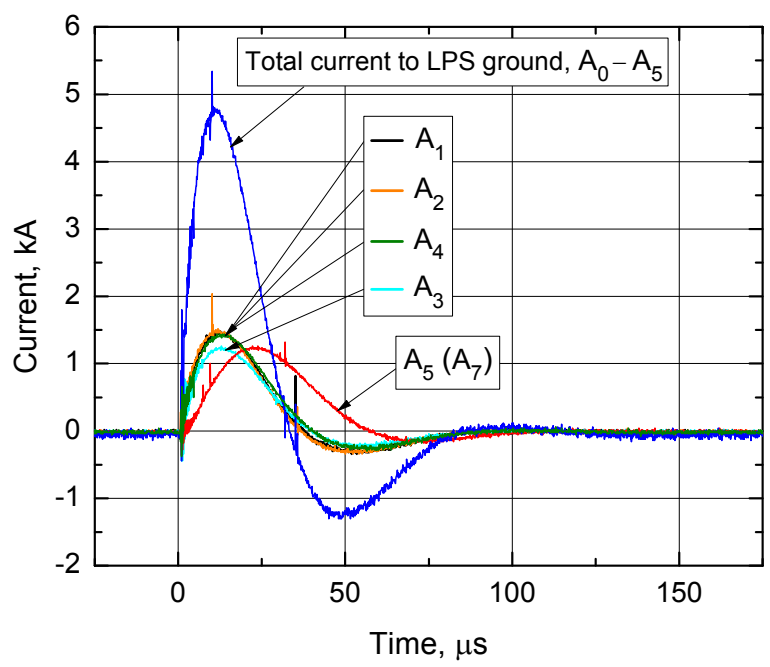

(c)

Fig. (10). Surge currents in individual LPS elements measured in the LPSs tested in Poland in 2007 and 2008; (a) LPS 1a; (b) LPS $1 \mathrm{~b} ;(\mathbf{c})$ LPS 2. 


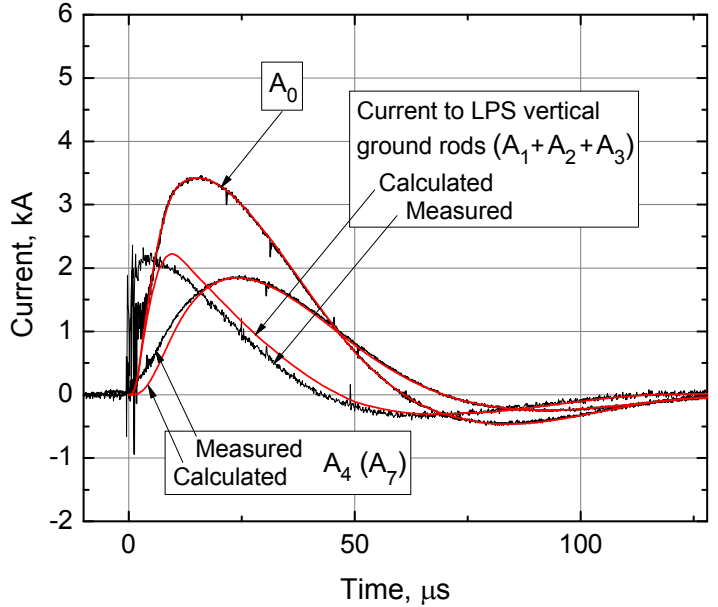

(a)

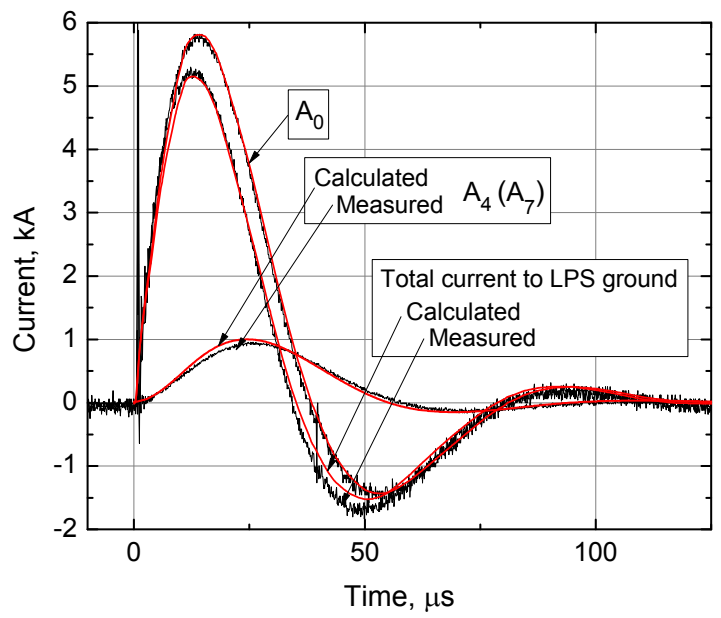

(b)

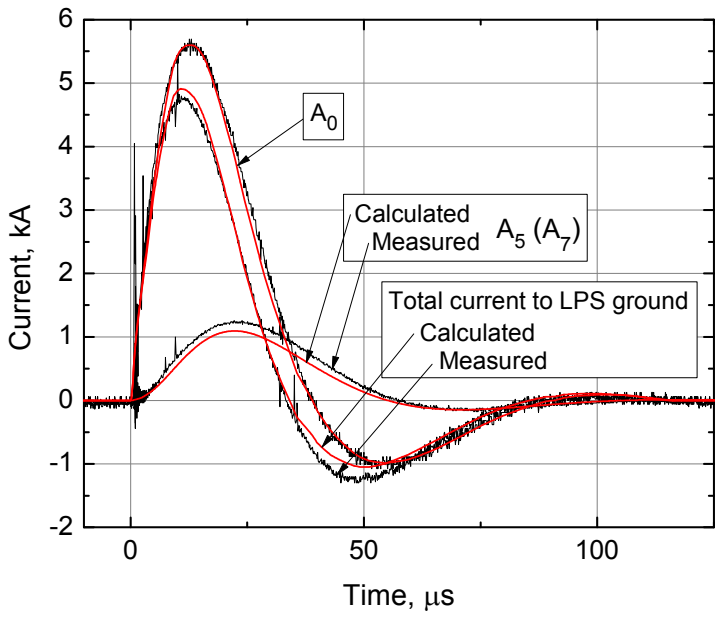

(c)

Fig. (11). Current waveforms measured and calculated in the LPSs tested in Poland in 2007 and 2008: the injected current $\mathrm{A}_{0}$, the total current flowing to local ground, and current $\mathrm{A}_{4}$ or $\mathrm{A}_{5}$ going to the remote ground; (a) LPS 1a; (b) LPS 1b; (c) LPS 2.

$\mathbf{t} \cdot \mathbf{E}^{i}=I_{l} Z_{w}-\frac{\mathrm{j} \omega \mu_{1}}{4 \pi} \int_{l} I_{l}\left(\mathbf{r}^{\prime}\right) G\left(\mathbf{r}, \mathbf{r}^{\prime}\right) d l$
The Green's function, $G\left(\mathbf{r}, \mathbf{r}^{\prime}\right)$ contains the Sommerfeld solution, which takes into account the effect of current dipoles immersed in a half-space conducting medium [11]. By employing the method of moments [9], the integral in Eq. (2) can be reduced to a set of linear equations from which currents in all defined segments may be calculated using standard numerical methods. Having the currents in segments calculated, the electric and magnetic field at any point of space may be determined as well.

Beside currents flowing along wire axes the leakage currents related to the electric field component perpendicular to wire surface are also taken into account. Note that it is very important during analysis of distributed currents in ground rods. The density $J_{\perp}(\mathbf{r})$ of leakage current is:

$$
J_{\perp}(\mathbf{r})=(\mathbf{n} \cdot \mathbf{E}) \sigma
$$

where $\mathbf{n}$ is a unitary vector normal to wire surface, whereas $\sigma$ stands for the conductivity of the medium around wires.

The results of these calculations are shown in Fig. (11) together with measured data. There is no electromagnetic coupling with lightning channel for the current surge generator experiments. However, effects of lossy ground and electromagnetic couplings between any conductors of whole experimental setup were taken into account in the calculations. The most visible differences between calculated and measured currents were found for the current flowing to ground in LPS 1a, Fig. (11a), while a quite good agreement for LPS $1 b$ and LPS 2 configurations is seen.

\section{CONCLUSIONS}

We have presented distributions of currents in different lightning protection systems (LPS) of test structures measured at Camp Blanding, Florida, in 2004 and 2005, during the rocket triggered lightning experiments, and at the Rzeszow University of Technology, Poland, in 2007 and 2008, during the current surge generator experiments.

In 2004, the mean value of the peak current entering at Camp Blanding the electrical circuit neutral was about $22 \%$ of the injected lightning current peak, while in 2005 it was about $59 \%$. In Poland, the values of the peak current entering the electrical circuit neutral for similar LPS configurations (but having smaller dc grounding resistances) were about $16 \%$ (LPS 1b) and 21\% (LPS2), respectively. For simple configuration LPS 1a this ratio was $56 \%$. Specifically, higher-frequency current components tended to flow to ground locally, while lower-frequency components traveled to remote ground, $50 \mathrm{~m}$ away. This effect was more pronounced for sandy soil in Florida and for simple configuration of LPS. Numerical simulations were also conducted both at the University of Florida, using the model based on the lumped circuit theory and full-wave approach in the frequency domain, and at the Rzeszow University of Technology, using the frequency domain full-wave approach. Different current waveshapes registered during experimental investigations were justified by numerical simulations. Considerable differences between results of the measurements and simulations conducted in Florida came from more complicated nature of experiments at Camp 
Blanding, Florida (for example, electromagnetic coupling with lightning channel). More experimental and theoretical research is needed. Therefore, a new project dedicated to the same subject is planned in the near future.

\section{ACKNOWLEDGMENT}

The project was partially supported by the National Science Center in Poland.

\section{CONFLICT OF INTEREST}

Declared none.

\section{REFERENCES}

[1] Rakov VA, Uman MA, Fernandez MI, et al. Direct lightning strikes to the lightning protection system of a residential building: triggered-lightning experiments. IEEE Trans Power Deliv 2002; 17(2): 575-86.

[2] DeCarlo BA, Rakov VA, Jerauld JE, et al. Distribution of currents in the lightning protective system of a residential building - part i: triggered-lightning experiments. IEEE Trans Power Deliv 2008; 23(4): 2439-46.
[3] Maslowski G, Rakov VA, Wyderka S, et al. Testing of lightning protective system of a residential structure: comparison of data obtained in rocket-triggered lightning and current surge generator experiments. High Volt Eng China 2008; 34(12): 2575-82.

[4] Li L, Rakov VA. Distribution of currents in the lightning protective system of a residential building - part ii: numerical modeling. IEEE Trans Power Deliv 2008; 23(4): 2447-55.

[5] Dawalibi F, Grcev L: An Electromagnetic model for transients in grounding systems. IEEE Trans Power Deliv 1990; 5(4):1773-81.

[6] HIFREQ User's Manual: low and high frequency electromagnetic field analysis buried and overhead conductor networks. SES \& Tech. Ltd., Montreal, Canada 1997.

[7] Guide for Measurement of Impedance and Safety Characteristics of Large, Extended or Interconnected Grounding. IEEE Stand 1991; $81(2)$.

[8] Bajorek J, Gamracki M, Maslowski G. Lightning coupling to overhead and buried conductors as frequency response function of the system in Proc. 27th Int. Conf. Lightning Protection. Avignon, France 2004; pp. 274-9.

[9] Johnson JHW. Generalized moment method in electromagnetic. USA: John Wiley \& Sons 1991.

[10] Harrington RF. Field Computation by Moment Methods. USA: Wiley IEEE Press 1993.

[11] Sommerfeld A. Uber die Ausbreitung der Wellen in der drahtlosen Telegraphie. Ann Phys 1990; 28: 665. 